\title{
PENGARUH SULFUR TERHADAP SIFAT FISIKA CAMPURAN PALE CREPE DAN SBR UNTUK KARET TAHAN PANAS
}

\section{THE EFFECT OF SULFUR ON PHYSICAL PROPERTIES OF PALE CREPE AND SBR BLENDS USED FOR HEAT RESISTANT RUBBER}

\author{
Arum Yuniari*, Nursamsi Sarengat, Sri Brataningsih Puji Lestari \\ Balai Besar Kulit, Karet, dan Plastik, Yogyakarta \\ *E-mail: arumyuniari@yahoo.com
}

Diterima: 10 Juli 2013 Direvisi: 12 September 2013 Disetujui: 2 Oktober 2013

\begin{abstract}
Sulfur plays an important role in the rubber vulcanization process especially in the formation of crosslinks. Heat resistant rubber made from mixing pale crepe and SBR requires the right amount of sulfur as crosslinking agent. The purpose of the study was to determine the effect of the addition of sulfur on the changes in physical properties before and after aging. Heat resistant rubber was made with variation of pale crepe/SBR: 80/20; 70/30; 60/40; 50/50 phr and sulfur variation of $1 ; 1.5$ phr. The results showed that sulfur was influential in the crosslinks formation. The addition of $1 \mathrm{phr}$ sulfur gave higher physical properties of the vulcanized with $1.5 \mathrm{phr}$ sulfur. The changes of physical properties after aging process of the vulcanized with sulfur 1 phr was lower than the vulcanized with sulfur $1.5 \mathrm{phr}$. Vulcanized pale crepe/SBR (70/30) with 1 phr sulfur could be applied as heatresistant rubber products.
\end{abstract}

Keywords: Pale crepe/SBR blends, sulfur, physical properties, heat resistant rubber

\begin{abstract}
ABSTRAK
Sulfur memegang peranan penting dalam proses vulkanisasi karet terutama dalam hal pembentukan ikatan silang. Karet tahan panas yang dibuat dari pencampuran pale crepe dan SBR membutuhkan sulfur dalam jumlah yang tepat sebagai crosslinking agent. Tujuan dari penelitian adalah untuk mengetahui pengaruh penambahan sulfur terhadap perubahan sifat fisika sebelum dan sesudah aging. Karet tahan panas dibuat dengan variasi pale crepe/SBR: 80/20; 70/30; 60/40; 50/50 phr dan variasi sulfur 1 dan 1,5 phr. Hasil penelitian menunjukkan bahwa sulfur sangat berpengaruh terhadap pembentukan ikatan silang. Penambahan sulfur $1 \mathrm{phr}$ memberikan sifat fisika lebih tinggi dari pada vulkanisat dengan sulfur 1,5 phr. Perubahan sifat fisika sesudah aging untuk vulkanisat dengan sulfur $1 \mathrm{phr}$ lebih kecil dari vulkanisat dengan sulfur 1,5 phr. Vulkanisat pale crepe/SBR (70/30) dengan sulfur 1 phr dapat digunakan untuk produk karet tahan panas.
\end{abstract}

Kata kunci: Pale crepe/SBR blends, sulfur, sifat fisika, karet tahan panas.

\section{PENDAHULUAN}

Proses vulkanisasi pada karet akan berpengaruh terhadap sifat fisikanya, yaitu: viskositas, kekerasan, tegangan putus, ketahanan kikis, compression set dan kelarutan dalam solven. Perubahan sifat fisika tergantung dari derajat crosslink. Derajat crosslink semakin panjang berpengaruh terhadap sifat fisika sedangkan derajad crosslink pendek akan berpengaruh terhadap sifat termal dan stabilitas oksidasi. Penggabungan (blends) dua atau lebih polimer merupakan cara yang ekonomis untuk mendapatkan bahan baru dengan sifat yang lebih unggul dari polimer itu sendiri, atau yang lebih 
dikenal rubber blends (Oleiwi et al., 2011).

Rubber blends sangat dibutuhkan oleh industri yang memproduksi karet tahan panas. Karet tahan panas dapat dibuat dari campuran karet alam dan karet sintetis. Rentang suhu dari sifat ketahanan karet terhadap panas dipengaruhi oleh bahan baku karet yang digunakan. Pada penelitian ini akan dibuat karet tahan panas dengan rentang suhu $60-100^{\circ} \mathrm{C}$. Fungsi karet tahan panas disini adalah untuk cover conveyor belt untuk mengangkut iron ore, pellets, casting sand, coke dan limestone. Karet tahan panas dibuat dari campuran pale crepe/SBR dengan variasi bahan pemvulkanisasi yaitu sulfur. SBR merupakan kopolimer dari stirena $\left(\mathrm{CH}_{2}=\mathrm{CH}\right.$ $\left.\mathrm{C}_{6} \mathrm{H}_{5}\right)$ dan 1,3-butadiena $\left(\mathrm{CH}_{2}=\mathrm{CH}-\mathrm{CH}=\mathrm{CH}_{2}\right)$. SBR dengan spesial grade mempunyai kandungan stirena dalam SBR sebesar 23,5\% berat. SBR mempunyai keunggulan dalam hal sifat ketahanan panas dan ketahanan aging, serta lebih toleran terhadap extender oil tanpa menyebabkan terjadinya penurunan sifat (deteoriozation in properties). Karetalamberasal dari lateks yang mengandung polimer isoprena (Oleiwi et al., 2011). Karet alam mempunyai keunggulan dalam hal tegangan putus, ketahanan terhadap cuaca, dan ketahanan kikis. Proses komponding pale crepe dan SBR membutuhkan sedikit sulfur dan akselerator lebih banyak. Pada pecampuran karet alam dan SBR, sistem pemasakan yang digunakan adalah vulkanisasi semi efisien, yaitu sulfur yang digunakan rendah (0,5-1 phr), jumlah akselerator (1,5-2,5 phr) akan membentuk crosslink disulphidic (C-SS-C), maka vulkanisat yang dihasilkan akan mempunyai ketahanan panas dan permanent set yang baik (Ames, 2001). Menurut TaghvaeiGanjali et al. (2009) beberapa activator seperti seng oksida, seng stearat dan kalsium oksida bila digunakan dalam proses vulkanisasi sangat mempengaruhi sifat mekanik.

Penelitian tentang campuran SBR dan karet alam dalam bentuk lateks dengan bahan pengisi clay telah dilakukan oleh Rahmatpour et al. (2008) dengan hasil campuran yang kompatibel, dan sifat mekanik yang baik. Manshaie et al. (2011) mempelajari pengaruh sistem vulkanisasi menggunakan iradiasi electron beam dan sulfur. Sinergi antara 2 (dua) akselerator $\mathrm{N}$-Benzylamineaminothioformamide (BIAT) dan TMTD sangat efektif dalam mempengaruhi sistem vulkanisasi (Thomas et al., 2011). Filler silika memberikan pengaruh yang signifikan terhadap sifat mekanik blend NR/SBR (Salimi et al., 2010). Goyanes et al. (2008) telah melakukan penelitian sifat termal campuran karet alam dan SBR. Penelitian tentang distribusi partikel carbon black pada campuran karet alam dan SBR telah diteliti oleh Le et al. (2008). Pengaruh filler ISAF carbon terhadap campuran karet alam, SBR dan XNBR telah diteliti oleh Pal et al. (2010). Penelitian tentang nanokomposit SBR dan karet alam dengan filler organoclay dilakukan oleh Gu et al. (2009) dan Tavakoli et al. (2012). Tujuan dari penelitian ini adalah untuk mengetahui perubahan sifat fisika vulkanisat pale crepe/SBR sebelum dan sesudah aging.

\section{BAHAN DAN METODE \\ Bahan Penelitian}

Bahan penelitian adalah: karet alam jenis pale crepe diambil dari pasaran di Yogyakarta dan karet sintetis jenis SBR merek Buna SE 1502 dengan kandungan stirena 23,5\%. Bahan aditif yang digunakan adalah: struktol sebagai homogenizer, HAF black jenis N330 sebagai filler, rhenosin GE 3071 dan parafinic oil sebagai plasticizer, pilnox TDQ sebagai antioksidan, zinc oxide $(\mathrm{ZnO})$ dan asam stearat sebagai activator, tetramethyl thiuram disulphide (TMTD) dan merchapto benzothiazole sulphenamide (MBTS) sebagai akselerator, dan sulfur sebagai bahan pemvulkanisasi.

\section{Peralatan Penelitian}

Alat yang digunakan dalam penelitian ini meliputi: two roll mill (hasil rekayasa dengan kapasitas $2 \mathrm{~kg}$ ), hydraulic press merek Toyoseiki A-652200500, tensile strength tester merek Troning Albert tipe QC II-M-18, dan hardness tester merek Toyoseiki (Durometer D).

\section{Metode Penelitian}

Penelitian dilakukan dengan tahapan sebagai berikut: Proses pencampuran bahanbahan menggunakan peralatan two rollmill, tahap awal adalah penggilingan pale crepe hingga plastis dengan suhu $40-50^{\circ} \mathrm{C}$ dengan waktu 5 menit dilanjutkan SBR digiling hingga plastis 
pada suhu $50-60^{\circ} \mathrm{C}$ selama 5 menit. Selanjutnya aditif ditambahkan ke dalam campuran dan digiling hingga plastis. Sebelum sulfur sebagai bahan pemvulkanisasi ditambahkan, kompon diambil dari two roll mill didinginkan selama 3-5 menit, dilanjutkan penggilingan kompon sambil ditambahkan sulfur. Setelah campuran homogen, kompon diambil dari two roll mill didinginkan dan dimasukkan dalam ruang kondisi $23 \pm 2^{\circ} \mathrm{C}$ selama 24 jam. Kompon untuk keperluan pengujian divulkanisasi menggunakan hydraulic press dengan tekanan $150 \mathrm{~kg} / \mathrm{cm}^{2}$ dan suhu $150^{\circ} \mathrm{C}$ dengan waktu sesuai rheometer.

Dalam penelitian ini dilakukan variasi pale crepe/SBR: 80/20; 70/30; 60/40; 50/50 phr dan variasi sulfur: 1 dan $1,5 \mathrm{phr}$.

Pengujian terhadap vulkanisat meliputi: tegangan putus dan perpanjangan putus sesuai ISO 37, kekerasan sebelum dan sesudah perlakuan aging pada suhu $100^{\circ} \mathrm{C}$ selama 70 jam sesuai JIS 6322 dan ketahanan kikis sesuai ISO 4649.

\section{HASIL DAN PEMBAHASAN Tegangan Putus}

Tegangan putus adalah pengujian mekanik secara statis dengan cara sampel ditarik dengan pembebanan pada kedua ujungnya dimana gaya tarik yang diberikan sebesar $\mathrm{P}(\mathrm{kg})$. Hasil uji tegangan putus erat kaitannya dengan kerapatan ikatan silang.

Tegangan putus vulkanisat karet tahan panas (Gambar 1) dipengaruhi kadar sulfur. Hasil uji

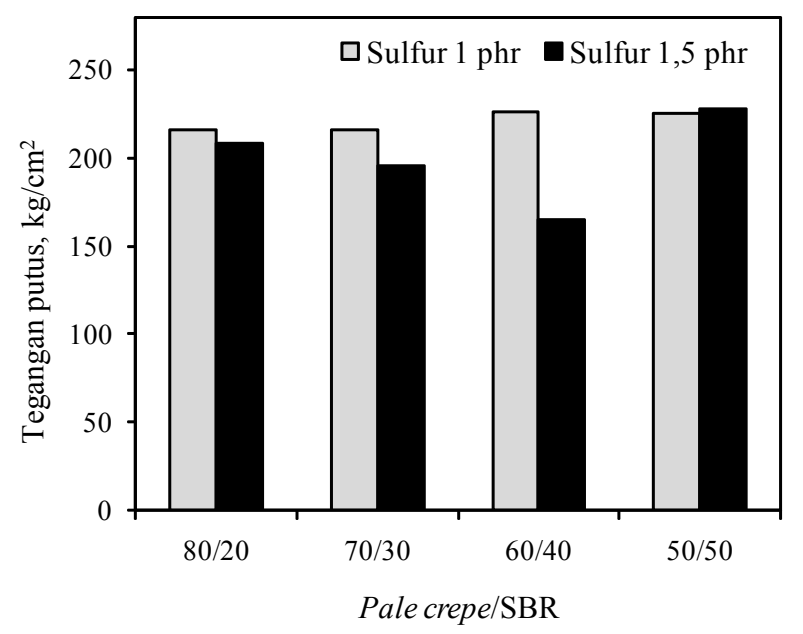

Gambar 1. Pengaruh perbandingan pale crepel SBR terhadap sifat tegangan putus tegangan putus vulkanisat dengan kadar sulfur 1 phr lebih tinggi daripada vulkanisat dengan kadar sulfur 1,5 phr. Tegangan putus vulkanisat sangat dipengaruhi oleh terbentuknya ikatan poly, di dan monosulphidic dan kerapatan ikatan silang. Semakin besar persentase terbentuknya crosslink polydisulphidic, semakin tinggi nilai tegangan putus dan elastisitasnya. Vulkanisat karet tahan panas dengan komposisi pale crepel SBR 50/50 dan kadar sulfur 1,5 phr mempunyai nilai tegangan putus sebesar $225 \mathrm{~kg} / \mathrm{cm}^{2}$. Jumlah sulfur berpengaruh terhadap tegangan putus hal ini didukung oleh penelitian Thomas et al. (2011).

\section{Perubahan Tegangan Putus Sesudah Aging}

Tegangan putus sesudah aging dimaksudkan untuk mengetahui perubahan sifat mekanik tegangan putus setelah dilakukan aging pada suhu $100^{\circ} \mathrm{C}$ selama 70 jam ditunjukkan pada Gambar 2. Hasil uji menunjukkan bahwa vulkanisat dengan kadar sulfur 1 phr memberikan hasil lebih baik dimana perubahan tegangan putusnya lebih rendah daripada vulkanisat dengan kadar sulfur 1,5 phr. Nilai terendah perubahan tegangan putus vulkanisat dengan sulfur $1 \mathrm{phr}$ adalah $1,45 \%$ dan vulkanisat dengan sulfur 1,5 phr adalah $22,32 \%$.

Hal ini menunjukkan bahwa dengan penggunaan jumlah bahan pemvulkanisasi yang tepat akan dihasilkan vulkanisat homogen dan tidak mudah mengalami pemutusan ikatan rangkap akibat pemanasan pada suhu tinggi.

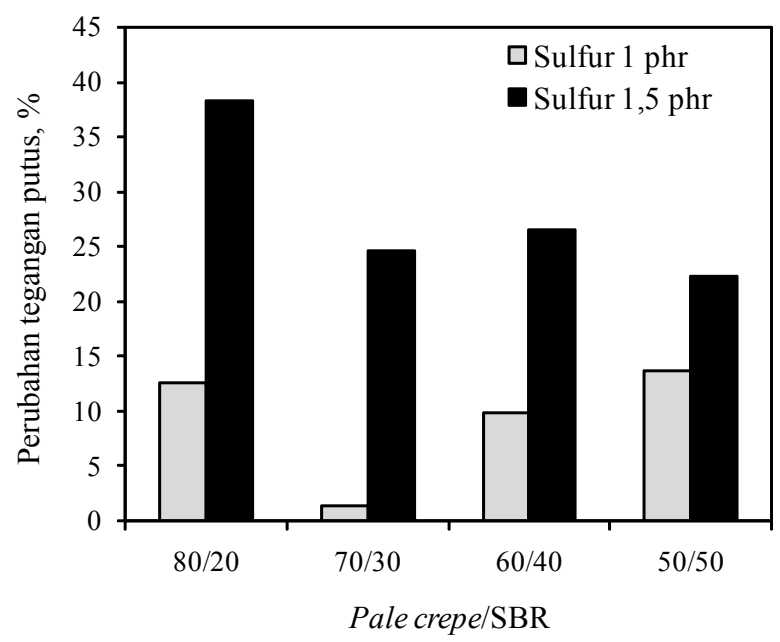

Gambar 2. Pengaruh perbandingan pale crepel SBR terhadap perubahan tegangan putus setelah aging pada suhu $100^{\circ} \mathrm{C}$ 


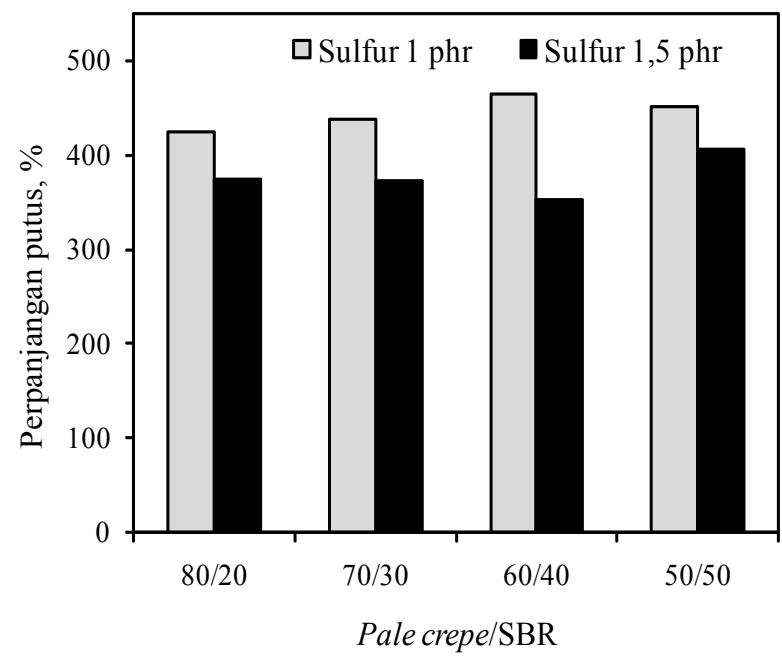

Gambar 3. Pengaruh perbandingan pale crepel SBR terhadap sifat perpanjangan putus

SBR merupakan karet yang mempunyai sifat tahan panas. Penggunaan SBR dalam campuran karet akan memberikan berpengaruh terhadap sifat ketahanan panas dari vulkanisat tersebut (Hasan et al., 2009). Hal ini membuktikan bahwa vulkanisasi semi efisisen yaitu menggunakan kadar sulfur rendah dan akselerator tinggi akan membentuk crosslink disulphidic (C-S-S-C) dan menghasilkan vulkanisat yang mempunyai ketahanan panas tinggi (Ames, 2001).

\section{Perpanjangan Putus}

Perpanjangan putus merupakan ukuran suatu bahan yang diartikan ketahanan material tersebut terhadap deformasi elastis. Semakin besar modulusnya maka semakin kecil regangan elastis yang dihasilkan akibat pemberian tegangan.

Perpanjangan putus vulkanisat karet tahan panas disajikan pada Gambar 3. Hasil uji menunjukkan bahwa vulkanisat dengan kadar sulfur $1 \mathrm{phr}$ memiliki nilai perpanjangan putus yanglebih tinggidibandingkan dengan vulkanisat dengan kadar sulfur 1,5 phr. Hal ini didukung oleh Ames (2001) yang menyatakan bahwa proses vulkanisasi dengan menggunakan sistem semi efisisen pada campuran pale crepe/SBR akan menghasilkan crosslinks polydisulphide, dimana dalam ikatan tersebut terdapat lebih dari3 atom sulfur sehingga vulkanisat semakin elastis, akibatnya perpanjangan putus tinggi. Sebaliknya, semakin besar kadar sulfur, percabangan sulfur

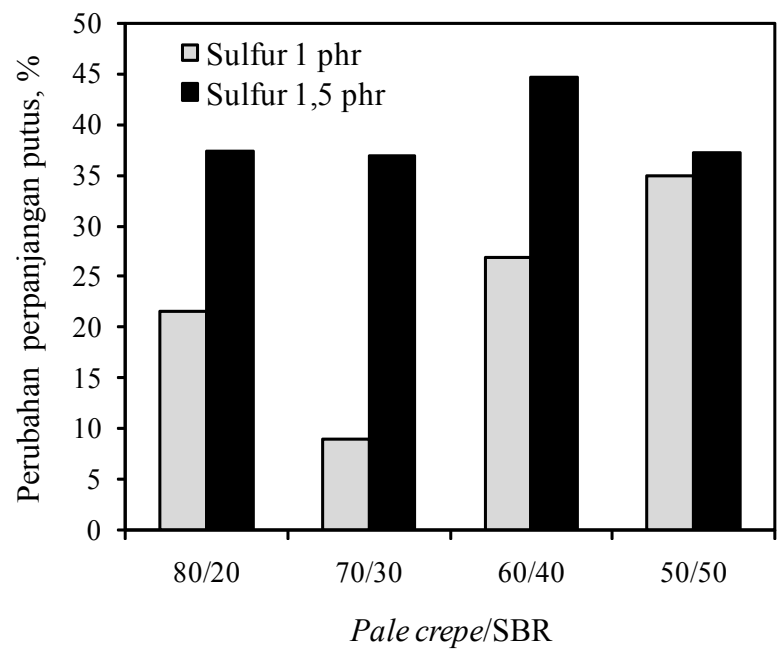

Gambar 4. Pengaruh perbandingan pale crepe/ SBR terhadap perubahan perpanjangan putus setelah aging

semakin turun vulkanisat menjadi kurang elastis sehingga nilai perpanjangan putus rendah.

\section{Perubahan Perpanjangan Putus Setelah Aging}

Perpanjangan putus sesudah aging dimaksudkan untuk mengetahui perubahan sifat mekanik perpanjangan putus setelah dilakukan aging pada suhu $100^{\circ} \mathrm{C}$.

Gambar 4 menunjukkan perpanjangan putus setelah dilakukan aging $100^{\circ} \mathrm{C}$ selama 70 jam. Perpanjangan putus sesudah aging untuk kedua variasi sulfur menunjukkan bahwa perubahan perpanjangan putus vulkanisat dengan kadar sulfur $1 \mathrm{phr}$ lebih rendah dibandingkan dengan vulkanisat dengan kadar sufur 1,5 phr. Hal ini menunjukkan bahwa vulkanisat masih elastis walaupun sudah mendapat perlakuan panas. Perpanjangan putus dengan perubahan terkecil yaitu vulkanisat dengan kadar sulfur $1 \mathrm{phr}$ sebesar $9 \%$.

\section{Kekerasan}

Kekerasan merupakan salah satu persyaratan yang dibutuhkan dalam pembuatan barang-barang teknik. Kekerasan campuran tergantung pada kekerasan komponenkomponennya. Kekerasan vulkanisat karet tahan panas terlihat pada Gambar 5. Vulkanisat dengan kadar 1,5 phr mempunyai kekerasan lebih tinggi dari pada vulkanisat dengan kadar 1 


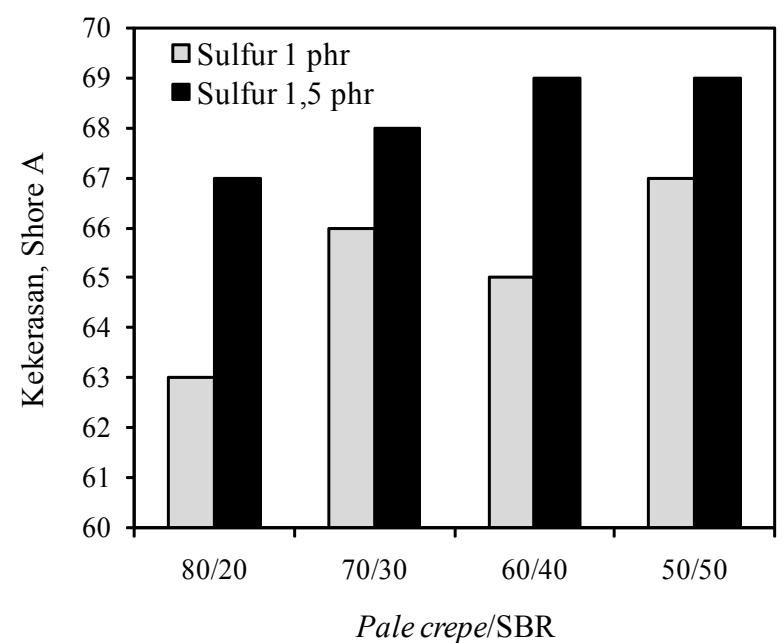

Gambar 5. Pengaruh perbandingan pale crepel SBR terhadap sifat kekerasan

phr, hal ini membuktikan bahwa semakin tinggi penggunaan sulfur vulkanisat semakin keras. Kekerasan tertinggi sebesar 69 Shore A terjadi pada vulkanisat pale crepe/SBR (60/40 dan 50/50) dengan kadar sulfur 1,5 phr.

Bila ditinjau dari perbandingan pale crepel SBR menunjukkan bahwa semakin tinggi kadar SBR kekerasan meningkat. Jumlah sulfur sangat mempengaruhi sifat kekerasan (Thomas et al., 2011).

\section{Ketahanan Kikis}

Ketahanan kikis menunjukkan kemampuan vulkanisat menahan gesekan yang dinyatakan dalam $\mathrm{mm}^{3}$. Ketahanan kikis sangat tergantung pada jenis karet dan ukuran partikel bahan pengisi. Ketahanan kikis vulkanisat karet tahan panas disajikan pada Gambar 6. Vulkanisat dengan kadar sulfur 1,5 phr ketahanan kikisnya lebih rendah dari vulkanisat dengan kadar sulfur 1 phr. Bila ditijau dari perbandingan pale crepe/ SBR menunjukkan bahwa semakin tinggi jumlah SBR ketahanan kikis turun. Hal ini disebabkan pale crepe mempunyai ketahanan kikis yang lebih tinggi dibandingkan SBR. Nilai ketahanan kikis terendah adalah vulkanisat pale crepe/SBR (80/20) kadar sulfur 1 phr.

\section{KESIMPULAN}

Polipaduan pale crepe/SBR sesuai digunakan untuk karet tahan panas dengan rentang suhu $60-100^{\circ} \mathrm{C}$. Penggunaan sulfur 1 phr memberikan sifat mekanik vulkanisat lebih

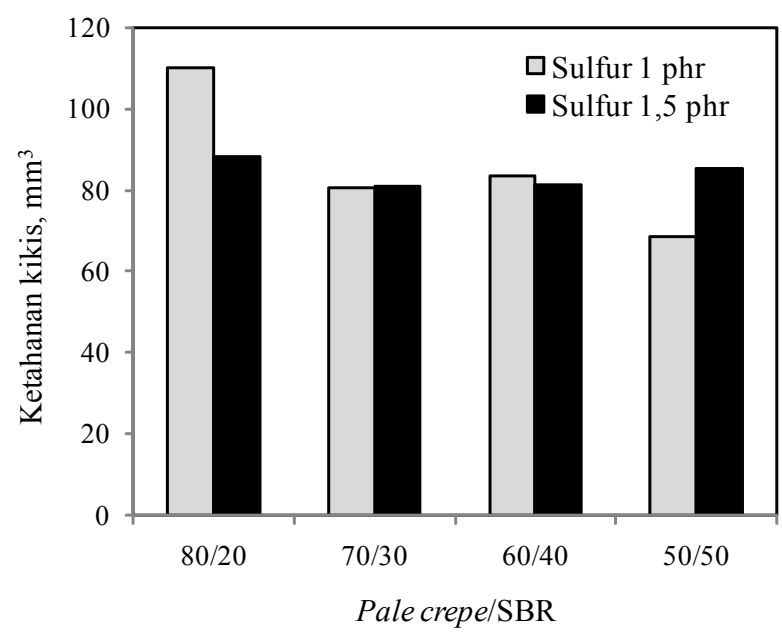

Gambar 6. Pengaruh perbandingan pale crepel SBR terhadap sifat ketahanan kikis

tinggi daripada sulfur 1,5 phr. Vulkanisat dengan sulfur $1 \mathrm{phr}$ memiliki sifat ketahanan terhadap aging lebih baik daripada vulkanisat dengan sulfur 1,5 phr. Vulkanisat dengan kandungan pale crepe lebih besar sifat ketahanan kikisnya tinggi. Kandungan sulfur tidak berpengaruh terhadap sifat ketahanan kikis.

\section{UCAPAN TERIMA KASIH}

Penulis mengucapkan terima kasih kepada Kepala Balai Besar Kulit, Karet, dan Plastik yang telah memberi kepercayaan untuk melakukan penelitian serta seluruh anggota tim yang membantu selama penelitian.

\section{DAFTAR PUSTAKA}

Ames, K., 2001. Rubber compounding in footwear, in De, S. K. and White, J. R. (Eds.). Rubber Technologist's Handbook, pp. 431-492, Rapra Technology Limited, UK.

Goyanes, S., Lopez, C. C., Rubiolo, G. H., Quasso, F., and Marzocca, A. J., 2008. Thermal properties in cured natural rubber/ styrene butadiene rubber blends, European Polymer Journal, 44(5): 1525-1534.

Gu, Z., Song, G., Liu, W., Li, P., Gao, L., Li, H., and $\mathrm{Hu}, \mathrm{X} ., 2009$. Preparation and properties of styrene butadiene rubber/natural rubber/ organo-bentonite nanocomposites prepared from latex dispersions, Applied Clay Science, 46(3): 241-244. 
Hassan, M. M., El-Megeed, A., and Maziad, N. A., 2009. Evaluation of curing and physical properties of NR/SBR blends using radiation-grafting copolymer, Polymer Composites, 30(6): 743-750.

Le, H. H., Ilisch, S., Kasaliwal, G. R., and Radusch, H. J., 2008. Filler phase distribution in rubber blends characterized by thermogravimetric analysis of the rubber-filler gel, Rubber Chemistry and Technology, 81(5): 767-781.

Manshaie, R., Khorasani, S. N., Veshare, S. J., and Abadchi, M. R., 2011. Effect of electron beam irradiation on the properties of natural rubber (NR)/styrene-butadiene rubber (SBR) blend, Radiation Physics and Chemistry, 80(1): 100-106.

Oleiwi, J. K., Hamza, M. S., and Nassir, N. A. A., 2011. Study of the effect of carbon black powder on the physical properties of SBR/ NR blends used in passenger tire treads, Engineering and Technology Journal, 29(5): 856-870.

Pal, K., Pal, S. K., Das, C. K., and Kim, J. K., 2010. Influence of fillers on NR/SBR/ XNBR blends: Morphology and wear, Tribology International, 43(8): 1542-1550.

Rahmatpour, A., Abdollahi, M., and Shojaee, M., 2008. Structure and mechanical properties of $50 / 50 \mathrm{NR} / \mathrm{SBR}$ blend/ pristine clay nanocomposites. Journal of Macromolecular Science, Part B: Physics, 47(3): 523-531.
Salimi, D., Khorasani, S. N., Abadchi, M. R., and Veshare, S. J., 2010. Optimization of physico-mechanical properties of silicafilled NR/SBR, Advance in Polymer Technology, 28(4): 224-232.

Taghvaei-Ganjali, S., Malekzadeh, M., Abbasian, A., and Khosravi, M., 2009. Effects of different activator systems on cure characteristics and physicomechanical properties of a NR/SBR blend, Iranian Polymer Journal, 18(5): 415-425.

Tavakoli, M., Katbab, A. A., and Nazockdast, H., 2012. NR/SBR/organoclay nanocomposites: Effects of molecular interactions upon the clay microstructure and mechanodynamic properties, Journal of Applied Polymer Science, 123(3): 18531864.

Thomas, S., Mathew, E. J., and Marykkutty, C. V., 2011. Synergic effect of n-benzylimine aminothioformamide secondary accelerator during sulfur vulcanization of a styrene-butadiene-natural rubber blend, Journal of Applied Polymer Science, 121(4): 2257-2263. 